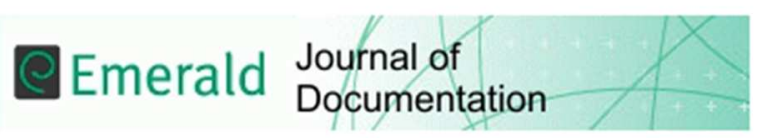

\title{
Researchers' attitudes towards the use of social networking sites
}

\begin{tabular}{|r|l|}
\hline Journal: & Journal of Documentation \\
\hline Manuscript ID & JD-04-2017-0051.R1 \\
\hline Manuscript Type: & Article \\
\hline Keywords: & Social Networking, Data Re-Use, Researcher, Behaviour, Attitudes, Profile \\
\hline
\end{tabular}

SCHOLARONE $^{\text {In }}$

Manuscripts 


\begin{abstract}
Purpose: The aim of this study is to better understand why many researchers do not have a profile on social networking sites (SNS), and whether this is the result of conscious decisions.

Design/Methodology: Thematic analysis was conducted on a large qualitative data set from researchers across three levels of seniority, four countries and four disciplines to explore their attitudes towards and experiences with SNS.

Findings: The study found much greater scepticism towards adopting SNS than previously reported. Reasons behind researchers' scepticism range from SNS being unimportant for their work to not belonging to their culture or habits. Some even felt that a profile presented people negatively and might harm their career. These concerns were mostly expressed by junior and midlevel researchers showing that the largest opponents to SNS may unexpectedly be younger researchers.
\end{abstract}

Research limitations: A limitation of this study was that the authors did not conduct the interviews, and therefore reframing or adding questions to specifically unpack comments related to attitudes, feelings or the use of SNS in academia was not possible.

Originality/value: By studying implicit attitudes and experiences, this study shows that instead of being ignorant of SNS profiles, some researchers actively opt for a non-use of profiles on SNS. 


\section{Introduction}

Today, academic standing may be linked to online standing: a researcher's online presence is an important channel for dissemination of expertise and achievements (Genoni et al., 2005; Mas-Bleda and Aguillo, 2013). Many researchers feel it is important to have a strong online presence in addition to having high quality publications in order to make a scientific impact. Researchers use these sites "to build, promote, and measure reputation" (Nicholas et al., 2015, p. 171), and to gain and maintain an "online academic identity" (Jordan, 2014, para. 2). Researchers reported that the use of social media increases the chances of their research being noticed (Weller, 2015) and they use, for example, Twitter as a professional medium for sharing and discussing publications. The more marketing researchers do, the more likely, it seems, that their research is noticed and cited (Eysenbach, 2011). Hyland (2011, p. 288) goes so far as to call it "almost obligatory for academics to maintain some kind of online presence".

Social networking sites (SNS) are the main venue where people establish their online presence through the creation of professional or personal profiles; many of them hosting several millions of users of various professional backgrounds, including researchers. The large number of users also attracts many researchers to make SNS and the use of SNS the object of their study. While not all researchers have an academic profile on SNS, there is "a sizeable number of scholars, even scholars who did not use platforms or only use them occasionally, who feels that emerging mechanisms and platforms will be the future and especially important for young scholars building a career. There is a sense that their time is coming" (Nicholas et al., 2015, p. 178).

The general consensus indicates that the future researcher will have an academic profile on a SNS. Studies describe researchers without an academic profile as the ones who "have fallen behind" (MasBleda et al., 2014, p. 350), who show a "general lack of awareness and understanding" (Abrizah et al., 2014, p. 257) and who "have much to learn" (Fiske, 2014, p. 441). These descriptions imply that whilst all researchers are not there yet, they should eventually be.

Today's researchers have to constantly make decisions on how to best promote their academic careers: where is the best publication venue for the next article, who is a trustworthy partner for a project, where is the best conference venue to find new partners, which grant proposals might be successful all within the constraints of time. If having an academic profile on SNS were indeed a successful and worthwhile way to promote academic careers, would researchers not pursue this line more strongly? Or put otherwise: are researchers really not there yet, or have they decided that they do not want to be there?

This article uses qualitative data to analyze researchers' attitudes towards and experiences with academic profiles on SNS. By looking explicitly at the wording researchers use when talking about academic profiles and SNS, we aim to discover whether researchers are indeed "behind the curve" and should be using academic profiles on SNS more for their academic careers or whether, on the other 
hand, researchers have made conscious decisions not to pursue this type of profile on SNS. The article will thus help inform developers in their design process of future SNS, particularly for academics.

The article is organized as follows: we first define SNS, and present an overview of research practices on academic use of SNS, structured according to their method of data collection: content analyses, questionnaires and qualitative interviews. We then describe our method and sample. The results section presents findings on researchers' experiences and feelings towards having an academic profile on SNS.

\section{Definition of social networking sites}

Social networking sites (SNS) are "web-based services that allow individuals to (1) construct a public or semi-public profile within a bounded system, (2) articulate a list of other users with whom they share a connection, and (3) view and traverse their list of connections and those made by others within the system" (Boyd and Ellison, 2007, p. 211). Some SNS are specifically aimed at the scientific community, for example Academia.edu. They provide additional features like sharing research papers, collaborating with colleagues or tracking citations. For these specialized sites, the term academic social networking sites (ASNS) is often used (Gruzd and Goertzen, 2013; Jeng et al., 2015). In what follows, we use the more general term SNS to include both academic and non-academic sites in our analysis, and we use the term "profile" only to refer to academic profiles, i.e. profiles for professional academic use.

Different kinds of SNS are used in academia. Researchers use classic SNS like Facebook, Myspace or Google + for professional purposes although they are not primarily aimed at them. As a microblogging service, Twitter differs from classic SNS, but conceptual borders are blurred as academics also use Twitter for similar purposes. Other networks are aimed at professionals but not exclusively at researchers, such as LinkedIn or XING, both launched in 2003. The former was acquired by Microsoft in 2016, reaching more than 467 million members in over 200 countries in 2017 (LinkedIn, 2017). The German online network XING reached over 12 million registered users in 2017 (XING, 2017). More recently, specialized ASNS directly addressing the research community such as ResearchGate, Academia.edu, ImpactStory and Google Scholar Citations have been developed. ResearchGate and Academia.edu were both launched in 2008, and permit researchers to upload papers and connect with other scholars. Academia.edu had more than 49 million users signed up in 2017 (Academia.edu, 2017), while the German network ResearchGate reports over 12 million users from 193 different countries (ResearchGate, 2017). Google Scholar Citations and ImpactStory focus more on individual users, their research output and scientific impact, and less on connecting and communicating. Finally, reference management tools like Mendeley, CiteULike or Zotero often provide social functions and the opportunity to construct a profile. Williams and Woodacre (2016) provide a more in-depth description of some of these sites. This indicates a great variety of SNS that academics could use to create their own profile. 
With an ever-growing number of SNS, a researcher's profile has become "an ubiquitous feature of scholarly life" (Hyland, 2011, p. 287). With the promises made by and the growing use of these sites, SNS have become a highly studied topic of interest. Related studies focus on scholarly impact measurements and altmetrics (e.g. Hoffmann et al., 2014; Li and Gillet, 2013; Mohammadi and Thelwall, 2014), or on different components or technical functions of particular or various networks (e.g. Codina, 2009; de Oliveira et al., 2011; Rohani and Ow, 2011). Previous studies examining users' attitudes towards SNS or the non-use of these sites exist, but concentrate mainly on non-academic usage (e.g., Hargittai, 2007; Lüders \& Brandtzæg, 2017; Ryan \& Xenos, 2011).

We have identified three distinct approaches to studying the use of SNS in academia: content analyses, questionnaires and qualitative interviews. We have classified studies according to their method of data collection because the choice of method influences what type of data can be collected and what results could be gained.

\section{SNS studies using content analyses}

Content analyses or similar approaches have been used to study SNS focusing either on the use of different social networks in academia or the population using these platforms. These studies have revealed on which SNS researchers have a profile, what a researcher's profile contains and what researchers offer as content on these sites. The average profile offers contact information, research interests, and current and previous positions (Hyland, 2011; Mas-Bleda and Aguillo, 2013). Fewer researchers provide a list of publications, information on education and a self-description. Teaching material or conference presentations are rarely presented. Only a small number of researchers offer information on current research projects (Mas-Bleda and Aguillo, 2013).

Bar-Ilan et al. (2012), investigating researchers from the bibliometric community and their online presence in social networks, reported that $84 \%$ of researchers in their sample had at least one institutional homepage and $70 \%$ had a LinkedIn account. In contrast, only $23 \%$ used a public Google Scholar profile and $16 \%$ had a Twitter account. Mas-Bleda and Aguillo (2013) focus on the group of highly cited researchers working at European institutions and their use of SNS. While most of the researchers had an institutional website of some kind, only $28 \%$ of them used any of the social websites examined (Google Scholar Citations, Mendeley, Academia.edu, LinkedIn, and SlideShare). The only non-academic site in the list, LinkedIn, was the most popular SNS. They conclude that overall researchers "had a low or very low presence in social sites" (Mas-Bleda and Aguillo, 2013, p. 346). Their participants were in majority male (95\%) and senior researchers, which might have affected the use of SNS.

Some studies concentrate on the academic usage and/or user population of individual networks like Academia.edu (Menendez et al., 2012; Thelwall and Kousha, 2014), Google Scholar Citations

(Ortega, 2015a) or Twitter (Holmberg and Thelwall, 2014). 
Researchers have identified disciplinary differences regarding the use of SNS in academia. Mas-Bleda and Aguillo (2013) found that the use of SNS was higher in the Social Sciences (40\%), Engineering (43\%) and Health Sciences (40\%) than in the Life Sciences (30\%) and Physical Sciences (28\%). Additionally, different research disciplines seem to prefer different SNS. While most researchers on Academia.edu belong to the Humanities and the Social Sciences, ResearchGate seems to attract mainly researchers from the Food Science and Technology, Biology and Biomedicine areas (Ortega, 2015b).

\section{SNS studies using questionnaires}

Studies using questionnaires investigate the use of SNS primarily through quantitative data gathered from asking closed questions to individuals. These studies focus, in particular, on the behavior of individual researchers, their personal preferences and attitudes regarding the use of SNS. While content analyses examined existing profiles to find out where researchers have profiles, questionnaires seek similar information by asking participants. Most of these previous studies focus on specific disciplines (Coppock and Davis, 2013; Haustein et al., 2014; Van Noorden, 2014) or on a single country (Coppock and Davis, 2013; Madhusudhan, 2012; Manca and Ranieri, 2016; Meishar-Tal and Pieterse, 2017; Nández and Borrego, 2013; Pscheida et al., 2014).

These studies have expanded prior work by providing researchers' reasons for using and concerns towards SNS. While many researchers have profiles on multiple platforms (Nández and Borrego, 2013), the preference for a specific SNS varies. Haustein et al. (2014), who studied researchers from the bibliometric community, report that researchers preferred LinkedIn (67.6\%) followed by Google+ (43.7\%), ResearchGate (21.1\%) and Academia.edu (21.1\%). Twitter was used by $43.7 \%$ and Mendeley by $23.9 \%$ of their questionnaire participants. While many scholars use a wide range of SNS, the most popular ones are non-academic networks like Facebook, Twitter or LinkedIn (Collins et al., 2016; Gruzd and Goertzen, 2013; Rowlands et al., 2011). Results of a large survey of the Nature Publishing Group (Van Noorden, 2014) show that awareness of different networks is much higher than their regular use. For example, while more than $88 \%$ of researchers said that they were aware of ResearchGate as a SNS, under half of them said that they visit it regularly (Van Noorden, 2014).

Like studies using content analyses, studies using a questionnaire detected disciplinary differences regarding the use of specific sites. While LinkedIn and ResearchGate show higher levels of use for the Natural Sciences, Social Sciences show the highest use levels for all other platforms (Jordan, 2014). Overall, disciplinary affiliation seems to have "a significant impact on academics' motivations and practices" (Manca and Ranieri, 2017, p. 134) regarding the use of SNS.

Researchers have various reasons to build a profile on a SNS and in consequence they also use these sites differently. Nández and Borrego (2013) report that researchers use other researchers' profiles to identify areas of research excellence and other researchers' activities, and to find collaborators for research projects. However, a quarter of all sampled researchers "claimed that they did not have any 
particular aim in mind when they created their profile for the service; they just wanted to be there as other colleagues were" (Nández and Borrego, 2013, p. 786). Likewise, researchers aim to connect with the professional community to disseminate their research output and to improve their visibility (Elsayed, 2016; Haustein et al., 2014; Nández and Borrego, 2013). Another important aspect is the use of profiles for job seeking and recruitment (Caers and Castelyns, 2011; Davison et al., 2011; Nández and Borrego, 2013).

The Nature survey showed that different SNS are used for different reasons. Respondents who had strongly taken up various SNS were asked about their activities while visiting these sites. On both ResearchGate and Academia.edu the "most-selected activity [...] was simply maintaining a profile in case someone wanted to get in touch - suggesting that many researchers regard their profiles as a way to boost their professional presence online" (Van Noorden, 2014, p. 127). Other activities mentioned were posting research related content, discovering peers, finding recommended research papers and tracking metrics. In contrast, Twitter users seem to be more active with a focus on activities that require a high user engagement such as following discussions or commenting on research. Jeng et al. (2015) focused on the network Mendeley, reporting that researchers primarily use it to manage documents and citations. Less than $15 \%$ used it for social functions like "managing existing academic friends" (11\%) or "expanding professional networks" (9\%) (Jeng et al., 2015).

Researchers reported having concerns about doing specific activities through SNS, such as dissemination of research: Jamali et al. (2015) report that the use of SNS (45.2\%) received the lowest ratings. This could be explained by the lack of trust in such platforms (Coppock and Davis, 2013). Privacy, data security, spamming and cyber-bullying issues were also mentioned by a majority of participants as problems (Madhusudhan, 2012). The benefits of SNS do not seem clear to all scholars as some see them as a "waste of time, or even dangerous" (Coppock and Davis, 2013, p. 214).

Moreover, researchers reported that it is a time-consuming burden (Jamali et al., 2015) to follow each SNS because having a profile requires repetitive entering and updating of data (Murray, 2014). Due to high workload, it is no surprise that many researchers do not spend a lot of time creating and updating their own profiles (Meishar-Tal and Pieterse, 2017). Nández and Borrego (2013) report that only $13 \%$ of their sample did monthly updates, $13 \%$ did weekly updates, $5 \%$ updated their profiles daily and most visits were short and below half an hour. Many researchers who have an account on Academia.edu do not follow other academics at all (26\%) or follow fewer than ten other researchers (56 \%) (Nández and Borrego, 2013). In summary, for most researchers it is not uncertainty in dealing with SNS or ignorance that is a barrier to usage, but conscious reasons: "more people were confident about how SNS could be used, but they had simply chosen not to use them for work-related purposes" (Donelan, 2016, p. 723). 


\section{SNS studies using qualitative interviews}

Studies of SNS through qualitative approaches, mainly interviews, focus on collecting open-ended data from smaller groups of participants and on gaining a more holistic understanding of their use.

These studies inspect in more detail researchers' attitudes towards profiles. Hyland (2011) complements his content analysis of 100 academic homepages with ten e-mail interviews. His results show that researchers are aware that their profiles are an advertisement for themselves as well as for the department and the university. Researchers also expressed the wish to separate private and business and to keep profiles to professional activities. Only a smaller group wished to show more personal items such as hobbies, too. Harley et al. (2010) studied how universities and their different stakeholders value emerging forms of scholarly communication. They observed a low uptake of SNS in academia and a focus on traditional forms of communication: "The sentiment that a handshake and eye contact provide the foundation of productive collaborations was near unanimous" (Harley et al., 2010, p. 16). Further, Abrizah et al. (2014, p. 257) reported a lack of trust in SNS, "which researchers largely saw as popularity indicators rather than anything more substantive" and Nicholas et al. (2015, p. 169) found that "most users were passive and did not fully engage with the social aspects of these platforms".

Existing interview studies mostly use a combination of convenience and snowball sampling (Abrizah et al., 2014; Harley et al., 2010). In addition, prior qualitative work has - even by qualitative research standards - a relatively small sample size (Hyland, 2011) or refers to just one country and culture (Abrizah et al., 2014; Harley et al., 2010). Nicholas et al. (2015) investigated the use and impact of SNS for different disciplines in four European countries (Computer Science in Poland, Economics in France, Humanities in Spain and Physical Science in Switzerland). The interviews were all conducted by different researchers in a local language and "because of the sensitivity of the topic" (Nicholas et al., 2015, p. 173) the interview sessions were not recorded. While this qualitative study is the only one with a large sample of 97 participants from various disciplines, the lack of transcripts did not allow a robust comparative analysis away from describing it by country.

\section{Summary}

Summarizing previous studies on the use of SNS:

- most previous research has been quantitative in nature, focusing on content analyses and closed questionnaires;

- today's researchers are aware of a broad range of SNS and have created profiles on these sites;

- although the usage of these platforms has grown, many researchers remain sceptical; and

- the reasons for this scepticism have only been partly explored. 
Our study bridges several research gaps: it uses a large sample of qualitative interviews across multiple countries and disciplines, and contributes to our understanding of whether academics are fully committed to having a profile on SNS, despite their benefits.

\section{Method \& Data Description}

The present qualitative study analyzes participants' experiences of and attitudes towards having a profile on and using SNS for academic purposes. To the best of our knowledge, this is the first study in the field to reuse qualitative interview data for which the authors had no influence on the sample design and the interview questions. Calls for data reuse are various (Kratz and Strasser, 2015; Tenopir et al., 2011), but few studies have actually reused data (Wallis et al., 2013), and much less qualitative data which depend strongly on context, the questions and the skill of the interviewer. Our study shows how data reuse makes possible new and important insights, but we also discuss limitations.

Data sets were collected as part of the Elsevier Connected program, which aimed to gather feedback on several new product concepts that could improve researchers' productivity and efficiency, while also understanding and prioritizing use cases of the most frequent and pressing activities of researchers in universities. The data sets were made available without any restrictions in terms of how to conduct the analysis or where to focus on. Sensitive information about participants or the company was deleted or pseudonymized. The research questions posed here emerged from analyzing interview transcripts.

Data gathering comprised three rounds of interviews, prototype testing, think-aloud tests, and questionnaires (see Figure 1). Insights from this study were used to support the development of a tool that is available, in beta version, in the SNS Mendeley in the form of an enhanced profile.

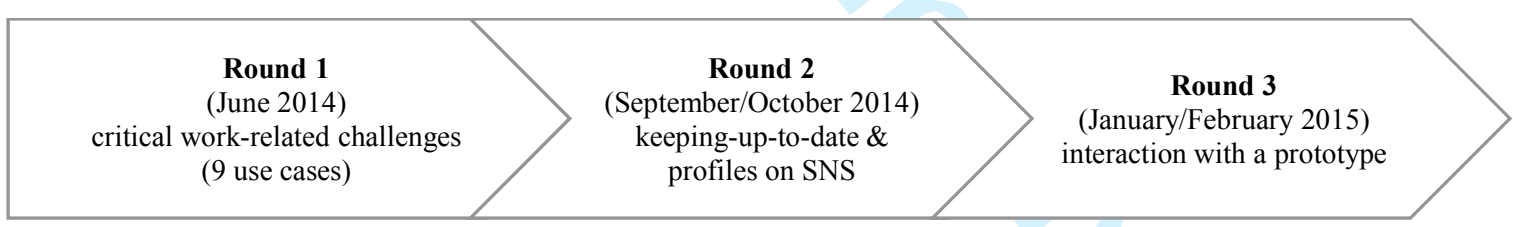

Figure 1. Rounds 1-3 of the Elsevier development program.

\section{Three interview rounds}

The first round explored nine use-cases described in Jacobson (2004): these were "keeping up-todate”, “online profiles”, “reviewing”, “reading”, “writing”, "publishing”, “connecting”, "funding”, and "storing data". The first round was exploratory, with questions that invited participating researchers to describe their daily work activities and challenges. The second round focused on "keeping up-to-date" and "online profiles", because participants reported these two use-cases as the ones of highest priority. Participants were asked about their online academic presence and use of profiles (e.g. Do you have a personal homepage or profile page?), what profiles they use professionally and to describe the purpose and content of their academic profiles (e.g. What do you consider to be the most important elements on the page?). During the study, interviewers referred to SNS as "profile page" "online profile" or "personal homepage", but they did not use the term SNS at any point. The interviewers did not 
explicitly probe for further components of social networks as outlined by Boyd and Ellison (2007) beyond profiles, but they also did not exclude them. The aim of the interviews was to have a starting point for discussion that was very likely shared by all participants and the component of a profile was the most likely place to start. Anonymous (2017) describe rounds 1 and 2 in more detail, and present findings on "keeping up-to-date". The third round explored, among other topics, participants' interactions with a prototype similar to a SNS dashboard. Participants were asked to discuss the pros and cons of features.

All interviews were conducted in English following detailed interview guides and were done face-toface where possible, or through WebEx, and audio transcribed verbatim.

\section{Study sample and sample characteristics}

Data gathering took place over nine months; some participants took part in all three rounds (Figure 1) while others only took part in one or two rounds. The analysis reported here focuses on the 81 participants (across all three rounds) who discussed their use, or non-use, of SNS. Participants came from four countries in three continents (Singapore, Germany, the United Kingdom, and the United States), and from four fields of study (Social Sciences and Humanities, Medical and Health Sciences, Natural Sciences, and Engineering and Technology Sciences), representing a broad range of academic disciplines and experiences. Participants were recruited following snowball sampling (Miles and Huberman, 1994) through an orchestrated campaign using face-to-face contacts by universities' research offices and libraries, and by reaching out to Mendeley users from these universities. Participants were grouped into three levels of seniority: Ph.D. students (junior level), academics with a $\mathrm{Ph} . \mathrm{D}$. and up to seven years of post-doctoral experience (midlevel), and academics with a Ph.D. and more than seven years of experience (senior level). An overview of the distribution across gender, domain and seniority of the 81 participants who discussed SNS can be found in Tables 1a and $1 \mathrm{~b}$. The following abbreviations are used during reporting: Field of Study: Engineering \& Technology (Tech), Medical \& Health Sciences (Health), Natural Sciences (Natural), and Social Sciences (Social); Gender: females (f) and males (m); country: Germany (GER), Singapore (SGP), United Kingdom (UK) and United States (US).

INSERT Table 1a. Overview of participants' field of study included in the analysis of this paper.

INSERT Table 1b. Overview of participants' level of seniority included in the analysis of this paper. Participants' presence on SNS

From the 81 participants who discussed SNS, 58 reported where they have a profile, and 23 did not report whether they have one. Of those 58 researchers, 18 reported having a single profile, of which 14 only had a profile on their institutional site. 34 reported having two or three profiles, and 6 reported more than four profiles. Figure 2 gives a visual overview per participant (rows) and where they reported having simultaneous profiles (columns). 


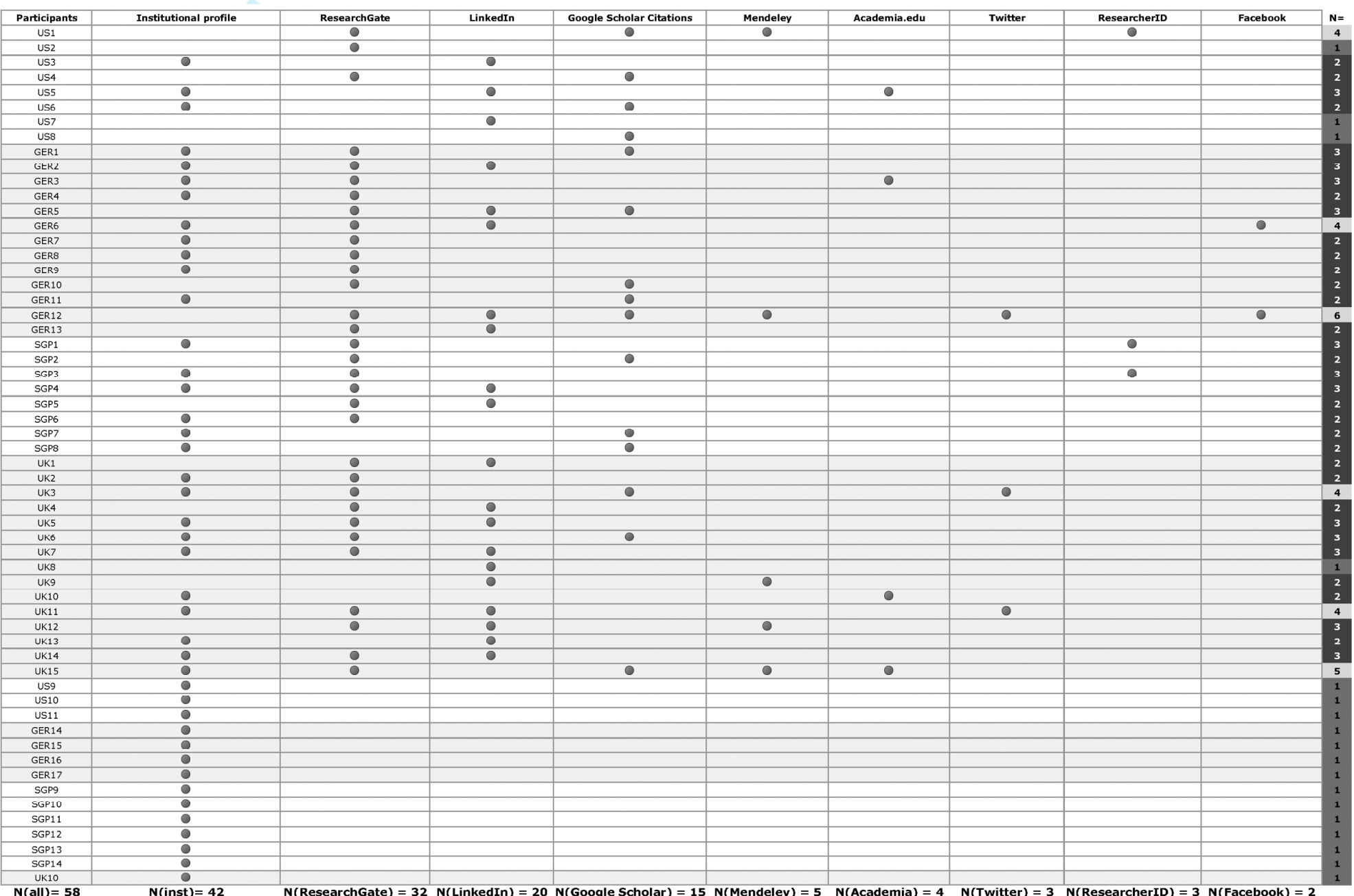

Figure 2. Overview of sites where 58 participants reported having profiles. 
32 researchers mentioned having a profile on ResearchGate, followed by LinkedIn where 20 researchers reported having a profile. LinkedIn was mentioned frequently in the UK (10) and in Germany (5), while researchers from Singapore (2) and the two US universities (3) made less use of LinkedIn. The latter was in particular a surprising result because with more than 128 million users in 2016, LinkedIn is very popular in the US (LinkedIn, 2016). A possible explanation is that researchers did not link it to their academic world and did not feel that they should mention LinkedIn as a site where they have a profile. They relied more on Google Scholar Citations. Mendeley, Twitter and Facebook were mentioned by some researchers, but in much lower numbers than previous studies have indicated (e.g. Haustein et al., 2014). Academia.edu was mentioned comparatively infrequently (4 of 58) and XING was not mentioned at all. Researchers reported preferring to use sites that allow the creation of specialized profile for researchers, and which therefore let them create a very specific type of profile.

Data analysis

The authors of this paper, who did not conduct the interviews, coded data sets in MAXQDA using thematic analysis, "a method for identifying, analyzing and reporting patterns (themes) within data" (Braun and Clarke, 2006, p. 79). After the generation of initial codes, insights about participants' feelings and attitudes towards, and academic professional use of, SNS emerged. In several coding rounds, themes were identified and the material coded accordingly. A total of 570 instances were coded in seven categories: SNS, use of social networking profiles, frequency of usage, aim of profiles, content of profiles, attitudes towards profiles, and use of other profiles. While participants were asked about their use of profiles, they were not asked about their attitudes towards SNS. This unusual approach to data analysis - not to analyze what has been asked but what has not been asked explicitly and discussed nevertheless - is one way to reuse qualitative data and thus to gain new insights into behaviors. The reported feelings and attitudes were spontaneously raised by the participants, i.e. without prompting or explicitly being asked for during the interviews. This indicates that issues around SNS matter to researchers, and also that they were even more likely to be expressing their true thoughts when responding spontaneously than they would if being required to create an answer to a specific question. As a result of grouping the different categories, two core themes emerged: 1) Experiences: researchers' experiences with profiles on SNS for professional academic use, and 2) Attitudes: researchers' feelings and attitudes towards profiles on SNS. We structure the results according to these two themes.

\section{Results}

Theme 1: Experiences with profiles on SNS for professional academic use.

Researchers' main aims for having a profile are summarized below. In line with previous studies, the core aim was raising awareness within the community "of the type of research work you're doing and what your interests are" (m, UK, junior, Health); or as one researcher succinctly stated it: "It's more 
like a sales pitch" (m, UK, midlevel, Health). Researchers create profiles, for example, to promote themselves to external reviewers when they are seeking tenure. The external community should be able "to know [their] background that is in terms of education. They would like to know about achievements. They would like to know about research areas" (f, UK, senior, Natural). It is therefore not surprising that researchers create profiles for job seeking: "I'm also in the academic journal market right now, so I think it's also important to have potential employers... give them an idea of my research in general" (m, US, junior, Social). However, not all researchers have similar experiences when they rely on their profile for job seeking. While a male junior faculty member in Medical \& Health Sciences from the UK reported that he had already received several job offers through his profile, another male junior faculty member remarked that "no one's ever contacted me out of the blue to take on a job" (m, US, junior, Tech). Researchers also expressed the wish to showcase their skills in a more compelling way than through a $\mathrm{CV}$ or a list of publications.

Researchers hope to create new networking opportunities, potentially finding new collaborations, by having a profile on SNS. The idea of one-entry point to a quick summary was frequently used by participants:

"That's the main purpose, to bring all the aspects of my works together into one place so when people do look me up that they can see everything that I do." (m, GER, midlevel, Natural)

In line with prior studies, showcasing teaching was not of great importance to researchers: "it's basically so that people know what I'm doing and they can get my papers and so on. So mostly for research rather than for teaching" ( $\mathrm{m}, \mathrm{SGP}$, midlevel, Tech). Only one male, senior UK faculty member from Natural Sciences, explicitly stated that he showcases current teaching activities. It might be that researchers display their current courses on their institutional profiles; but they did not talk about it. Many universities use tools to automatically include courses on institutional profiles and thus researchers may not experience it as something they provide actively.

While participants were not explicitly asked whether or how they use other researchers' profiles, many participants reported that they use profiles to attract and check new staff members: "the only time I really look up somebody's profile is if that's somebody that we're looking to hire" (m, US, junior, Tech). Participants commented on the value of being able to see other researchers' profiles beyond their publications:

"journals are really good for keeping up on the scholarship, but there are a lot of projects [...] going on with people who are working on building web content, and it's a little harder to find, because it doesn't work well in a traditional journal environment" (m, US, junior, Social).

"I can tell this guy is really smart because he's done XYZ universities and he's got papers in only the best of the best" (m, US, junior, Tech). 
In line with previous studies (Caers and Castelyns, 2011; Nández and Borrego, 2013), researchers reported using others' profiles for networking and recruitment:

"it's a mechanism for people to find out who you are and what you do, so there's a networking aspect to it" (m, US, senior, Tech).

Researchers mentioned most frequently that they list publications, a quick summary, awards and fellowships, contact details, past reviewing expertise, collaborators and links to laboratories.

Supporting prior studies, content on expertise and organizational work were each only mentioned by one or two participants across all interviews.

Researchers reported that they rarely sit down and actively work on their profiles. However, while researchers expressed the wish for a profile that is not time consuming, they equally wish to be able to personalize their profile and control what is displayed. The reported wish to spend minimum time on preparing or maintaining profiles contradicts the wish to showcase more than just publications.

\section{Theme 2: Feelings and attitudes towards profiles on SNS}

Researchers have profiles on different SNS to fulfill various aims. While this may indicate that researchers embrace profiles as part of their academic life, some profiles resemble footprints that researchers have left at some point while walking by, instead of acting as a flag to indicate that this place belongs to someone. Participants have something online, but they frequently have trouble remembering where they have a profile or what they have on it. 60 out of the 81 participants that explicitly talked about SNS reported specific feelings and attitudes towards having profiles on SNS. They describe their profiles as "something at ResearchGate" (m, GER, midlevel, Natural) and they say that "I believe we are... all the staff here, all the faculty here have a research profile page" (m, SGP, midlevel, Natural). Supporting previous findings (Haustein et al., 2014; Nández and Borrego, 2013), while many researchers have an account, only a small number of researchers actually use them. Researchers may have a presence on SNS, but they are not present.

Having a presence without being present is also reflected in researchers' attitude towards keeping profiles up-to-date. One female researcher describes it as a "passive thing" (f, UK, midlevel, Social). While many researchers have profiles, they are "low on [the] priority list to keep [them] up to date" ( $\mathrm{m}, \mathrm{UK}$, senior, Natural) and it is "not something [they are] really dedicating a lot of time to" (m, UK, midlevel, Health).

There is, however, a difference between the frequencies of checking and updating profiles between countries. In Germany, the spectrum ranges from a bi-weekly update to an update when there is a change in profession to the point that they do "not do much with it" (m, GER, midlevel, Natural). US and Singapore researchers reported doing only annual updates. In contrast, nearly two thirds of UK researchers reported updating their profile bi-weekly or monthly. Natural Sciences researchers update 
their profile most frequently, followed by Engineering \& Technology Sciences and Medical \& Health Sciences. Social Sciences researchers remarked unanimously that they do not do much with it.

Not all researchers seem to like this new academia demanding a profile to be present in a networked environment. Researchers from the hard sciences - Engineering \& Technology, Medical \& Health Sciences and Natural Science - experience it as "spamming" (m, GER, midlevel, Tech) and a "waste of time" (m, GER, senior, Natural), and Social Science researchers describe it as "gossiping" (f, GER, junior, Social). While more male researchers describe profiles as spamming, more females felt it was like gossiping and "measuring people" (f, US, midlevel, Natural). One junior female reported:

"it tricks me, like the intent is to be like this person has a lot of followers so they are important and I actually don't want to see that because I wanted to (find) without their kind of popularity influencing me." (f, US, junior, Social)

The effectiveness of SNS as a way for advertising oneself is clearly disputed. Researchers were concerned that people are judged by their number of followers:

"You open somebody's page and, like, oh, they don't have many followers, so they're probably not very important, so I don't have to worry about them" (f, US, midlevel, Natural).

They are also aware that the profile itself does not automatically lead to collaboration with the most cited researchers: "I want to follow famous people, but [...] famous people don't want to follow me" (f, SGP, midlevel, Tech). They feel that "right now [...] collaboration mainly happens through personal interaction, not on the social networking sites" (m, US, senior, Tech).

Hyland (2011) reported that researchers expressed the wish to separate private and business on their profiles and this finding was supported by the present data. Researchers want to have the "papers and publications and the people and groups, [they] want them to be in two different places" (f, SGP, junior, Tech). Information on profiles is experienced as "so public" (m, US, junior, Natural) and researchers "feel a little bit too exposed" by these sites (m, GER, midlevel, Natural). This feeling of exposure was also manifested for displaying current reviewing activities. A UK researcher said that he "wouldn't really be that comfortable saying [he] review[s] for this specific journal and putting it out in public" (m, UK, midlevel, Natural) and a junior faculty member stated that listing current reviewer activities will lead to "some awkward phone calls [in] the scientific community" (f, SGP, junior, Tech).

SNS seem to belong to a different world than that of academia. Researchers are concerned that they "really have no time looking for what is happening in other people's social life" (m, US, senior, Health) and that they are "not very curious in the personal affairs of people, their positions and stuff like that" ( $\mathrm{m}$, GER, senior, Social). It was not so much that researchers reported negative attitudes towards SNS as that they felt that these sites were part of a different world: "I don't have like a Twitter account, I'm really unique there" (m, US, senior, Natural), "I don't do a whole lot of social network 
type stuff" (m, US, junior, Tech) or "I do not use too much social network" (f, GER, senior, Natural). As previously mentioned, a large group of researchers stressed a lack of active presence on SNS. We grouped profile-related attitude extracts from the 60 participants (16 junior, 21 midlevel and 23 senior researchers) into four attitude categories (Figure 3): 1) profiles on SNS are or can be useful for me: quotes reporting positive, useful experiences with profiles on SNS or where participants expect that profiles will be useful. 2) Profiles on SNS are not important enough for me: quotes describing profiles as a low priority or worse as spamming. 3) Profiles on SNS don't work for me: quotes describing cultural and habitual reasons for not using profiles on SNS. 4) Profiles on SNS may hurt my career: quotes expressing some form of clear rejection towards profiles on SNS. Figure 3 shows the likelihood of uptake of academic profiles on SNS and differences between seniority levels.

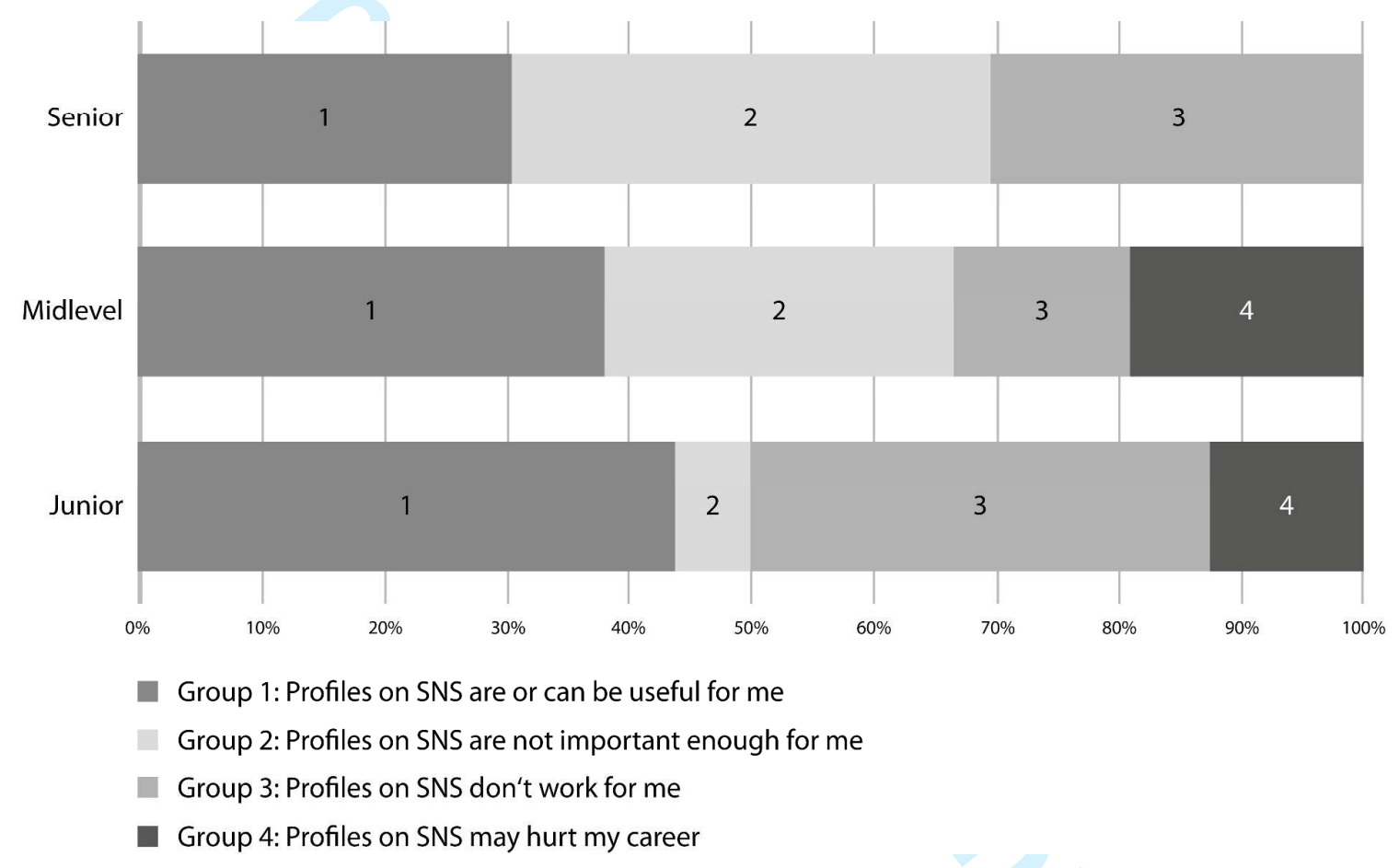

Figure 3. Likelihood of uptake of academic profiles on SNS from group 1 very likely (left side) to group 4 highly unlikely (right side) grouped by level of seniority.

Figure 3 reads from left to right showing high likelihood of uptake of profiles on SNS on the left side to a very unlikely uptake on the right side. Group 1 participants already see a personal benefit in using SNS: either they already use them or, with the right tool, are very likely to start using them. A female junior researcher said that she liked it

"when people [...] have so a little thing at the end but it's a little bit of access to who they are, so, like a run marathons or some kind of hobby or feature whether -- are they humans" (f, US, junior, Social). 
Group 2 participants do not reject profiles fundamentally; they just do not consider them important enough to spend time on them. With the right tool and the right benefit, they might be convinced that a profile on SNS will be useful. This is for example reflected in the statement of a midlevel researcher who said that he does not

"have enough time during the day to get all [his] writing and [his] proposals done, to then spend hours updating research profiles" (m, US, midlevel, Natural).

SNS will have a more difficult time persuading Group 3 participants because profiles on SNS do not fit in their practice nor belong to their culture; and changing culture and habits can be hard (Coppock and Davis, 2013). A junior researcher called it "like gossiping but for people in different stages of career" (f, GER, junior, Social).

Group 4 participants are most likely to reject having a profile on SNS, because they already fear for or have experienced negative effects with them. For example a junior researcher called his Google Scholar profile "so public" (m, US, junior, Natural) and a midlevel researcher painted the scenario that

"Let's say, I forgot to click follow my good friend cum supervisor, he'll be pissed at me for my entire career" (m, SGP, midlevel, Tech).

Figure 3 suggests that there may be differences in representativeness of seniority level across these four groups. In Group 1, the three levels of seniority are well balanced: from juniors $(\mathrm{N}=7)$ to midlevel $(\mathrm{N}=8)$ and senior $(\mathrm{N}=7)$ researchers, they all perceive benefits using SNS. In Group 2, the midlevel $(\mathrm{N}=6)$ and senior $(\mathrm{N}=9)$ researchers consider $\mathrm{SNS}$ as not being important enough to spend time on them. With the exception of one female junior researcher from the States, juniors did not explicitly express this feeling. Group 3 represents researchers from all seniority levels again (junior $(\mathrm{N}=6)$, midlevel $(\mathrm{N}=3)$, senior $(\mathrm{N}=7))$. This means that cultural and habit differences are not related to age in this situation. There were also young researchers who did not feel that SNS work for them. Yet Group 4 does not contain a single quote from a senior researcher - meaning no senior researcher expressed concern about SNS being potentially damaging. This may be because senior staff feel more secure in their careers, so presence or absence on SNS is a less significant factor for them. The largest opponents to SNS may unexpectedly be younger researchers.

\section{Limitations of the study and reuse of qualitative data}

This study has limitations that should be taken into consideration. The first one is that it reuses qualitative interview data originally collected with the aim to gather insights to inform and support the development of a tool available in Mendeley. This means that questions asked during interviews were mostly directed to explore this specific SNS and gain insights related to usability and design. In addition, the authors of the paper were not the ones conducting the interviews; therefore we could not reframe or add questions to specifically unpack comments related to attitudes, feelings or the use of 
SNS in academia. Since part of the recruitment used Mendeley users, figure 2 shows that their profile on Mendeley was not present on researchers' minds. It is therefore likely that participants have profiles on other sites than the ones they mentioned but these leads may not have been pursued further because they were not relevant for the initial purposes of the study. The results show the profiles that were present on participants' minds.

The next limitation is the sampling strategy, which used researchers who were also Mendeley users. To some extent, this could limit the applicability of our findings as they could be representative only of Mendeley users. This bias was reduced through the second recruitment approach to use informal contacts at senior university levels, which gained participants who probably normally would not partake in such a study due to lack of time - in particular the large number of senior researchers that were recruited. However, although it does not represent all academic researchers, the sample of the study was large and diverse by qualitative research standards. We believe that based on the breadth of participants' backgrounds, results would generalize well across academic disciplines and institutions, and to non-Mendeley users.

Another limitation of the study is time. Particularly in this topic, new research is constantly conducted as new technology is developed and people's attitudes evolve. This manuscript was initially written in 2016 with datasets collected through 2014 and 2015. The age factor is a limitation that is inherent to data reuse. Since the time when data sets were collected (2014-2015), researchers' preferences may have evolved or changed. However, many comments seem to be time agnostic and more related to working preferences which are unlikely to drastically change in a short timeframe.

As with any empirical study, it would be good to see follow-up studies and further explorations that test the validity and generalizability of findings reported here. For example, validation of these findings could be gained by re-using previous datasets that reported concerns (e.g. Nicholas et al., 2015), focusing the analysis on seniority level or conducting new studies that focus explicitly on younger researchers.

\section{Conclusion}

This article started out by questioning the general consensus that the future researcher will have a profile or would be interested in having one on SNS. Previous studies imply that researchers may not have fully adopted SNS, but they predict that the time has come and that researchers will soon embrace SNS for their academic work. Furthermore, the literature review revealed that content analyses and questionnaires were the dominant approaches to gather data. While the majority of publications present how and how much researchers have already adopted SNS, a few gave voice to concerns expressed by researchers. Reasons behind the concerns were lacking or not explicitly stated. Our qualitative study with a diverse sample of researchers bridges this gap and sheds light on researchers' feelings and attitudes towards SNS not explicitly and expansively explored in prior studies. We focused on better understanding whether researchers were or are not there (i.e. they have 
or do not have a profile on SNS), or they had actively decided that they do not want to be there (i.e. they have no interest in having a profile on SNS). Our main finding is that there is much greater scepticism towards creating a profile on and regularly using SNS for academic purposes than previously reported. Researchers often have a presence on SNS, but they are not present on these sites (e.g. profiles are outdated and infrequently used, missing key information).

The analysis also revealed that the reasons behind researchers' scepticism range from SNS being unimportant for their work to not belonging to their culture or habits. Some even felt that a profile measured and tricked people negatively, and might harm their career. The differences in seniority level illustrated that the group that would be less likely to adopt SNS for academic purposes may be the junior and midlevel researchers. This finding can help inform the characteristics of future SNS and provide new directions to developers.

Based on these findings, what researchers $d o$ and say are not always consistent, as the clear difference between having a profile on SNS and actually being present in the online world indicates. While for some researchers SNS are useful tools, a significant proportion of researchers agree that SNS are not useful or do not make a difference for their work. Furthermore, just having a profile on SNS is not an indicator of being an active user or having a strong online presence in the field as many researchers do not keep profiles updated and in some cases they even forget in which SNS they have them. However, this important difference between these concepts (having a profile and being present) has not been explicitly reported in prior studies, and both concepts are often misunderstood: researchers think that just by creating a profile on SNS they will be automatically connected and benefit from the online community. We recognize the limitations of this study, particularly the fact that findings were drawn from a qualitative sample of Mendeley users, but we also believe that a deeper understanding of the implications that this difference may have for academia and SNS would help better support researchers' work needs and habits.

To conclude, we argue that researchers have not "fallen behind" (Mas-Bleda et al., 2014, p. 350). Instead, many of them are already ahead and have left SNS. Researchers do not show a "general lack of awareness and understanding" (Abrizah et al., 2014, p. 257) and do not "have much to learn" (Fiske, 2014, p. 441). On the contrary, many researchers from the sample expressed very clearly that they have made a conscious decision to leave SNS away from their world or, at least, they are not interested in using SNS more actively, because they have evaluated them and concluded that they are a waste of time, not fitting with their way of working or even being harmful. This is not a lack of understanding, but an indication of high understanding. Instead of being ignorant, some researchers actively opt for a non-use of profiles on SNS.

\section{References}

Abrizah, A., Badawi, F., Zoohorian-Fooladi, N., Nicholas, D., Jamali, H.R. and Norliya, A.K. (2014), "What scholarly channels and resources do authors trust to read, cite and publish in? A 
Malaysian study", in Noorhidawati, A., Abrizah, A., Diljit, S., Edzan, N.N., Sinnasamy, J., Kiran, K., Koh, A.P., Lisdar, A.W., Mahbob, Y., Noor Harun, A.K., Pauziaah, M. and Ratnawati, M.A. (Eds.), Library: Our Story, Our Time, Our Future: Proceedings of the International 5th Conference on Libraries, Information and Society (ICoLIS) 2014, University of Malaya, Kuala Lumpur, Malaysia, pp. 245-262.

Academia.edu (2017), “About Academia.edu”, available at: https://www.academia.edu/about (accessed 9 August 2017).

\section{Anonymous (2017), DETAILS OMITTED FOR DOUBLE-BLIND REVIEWING}

Bar-Ilan, J., Haustein, S., Peters, I., Priem, J., Shema, H. and Terliesner, J. (2012), “Beyond citations: Scholars' visibility on the social Web", in Proceedings of the 17th International Conference on Science and Technology Indicators, pp. 98-109.

Boyd, D.M. and Ellison, N.B. (2007), "Social Network Sites: Definition, History, and Scholarship", Journal of Computer-Mediated Communication, Vol. 13 No. 1, pp. 210-230.

Braun, V. and Clarke, V. (2006), "Using thematic analysis in psychology", Qualitative Research in Psychology, Vol. 3 No. 2, pp. 77-101.

Caers, R. and Castelyns, V. (2011), "LinkedIn and Facebook in Belgium: The Influences and Biases of Social Network Sites in Recruitment and Selection Procedures", Social Science Computer Review, Vol. 29 No. 4, pp. 437-448.

Codina, L. (2009), "Science 2.0: Social networks and online applications for scholars", Hipertext.net, Vol. 7, available at: https://www.upf.edu/hipertextnet/en/numero-7/ciencia-2-0.html (accessed 9 August 2017).

Collins, K., Shiffman, D. and Rock, J. (2016), "How Are Scientists Using Social Media in the Workplace?", PLoS ONE, Vol. 11 No. 10, e0162680.

Coppock, E.G. and Davis, L. (2013), "Status of the adoption of social media in the scientific research community”, Information Services \& Use, Vol. 33 No. 3-4, pp. 203-217.

Davison, H.K., Maraist, C. and Bing, M.N. (2011), "Friend or Foe? : The Promise and Pitfalls of Using Social Networking Sites for HR Decisions", Journal of Business and Psychology, Vol. 26 No. 2, pp. 153-159.

De Oliveira, J.P.M., Lopes, G.R. and Moro, M.M. (2011), “Academic Social Networks”, in de Troyer, O. et al. (Eds.), Advances in Conceptual Modeling. Recent Developments and New Directions, Springer, Berlin, Germany, pp. 2-3.

Donelan, H. (2016), "Social media for professional development and networking opportunities in academia", Journal of Further and Higher Education, Vol. 40 No. 5, pp. 706-729.

Elsayed, A.M. (2016), “The Use of Academic Social Networks among Arab Researchers: A Survey”, Social Science Computer Review, Vol. 34 No. 3, pp. 378-391. 
Eysenbach, G. (2011), "Can tweets predict citations? Metrics of social impact based on Twitter and correlation with traditional metrics of scientific impact", Journal of Medical Internet Research, Vol. 13 No. 4, e123.

Fiske, P. (2014), "Nurture your online persona”, Nature, Vol. 516, pp. 441-442.

Genoni, P., Merrick, H. and Wilson, M. (2005), "The use of the Internet to activate latent ties in scholarly communities", First Monday, Vol. 10 No. 12, available at: http://firstmonday.org/htbin/cgiwrap/bin/ojs/index.php/fm/article/viewArticle/1301/1221 (accessed 9 August 2017).

Gruzd, A. and Goertzen, M. (2013), "Wired Academia: Why Social Science Scholars Are Using Social Media", in System Sciences (HICSS), 2013 46th Hawaii International Conference on System Sciences, IEEE, New York, NY, pp. 3332-3341.

Hargittai, E. (2007), "Whose Space? Differences among users and non-users of social network sites", Journal of Computer-Mediated Communication, Vol. 13 No.1, pp. 276-297.

Harley, D., Acord, S.K., Earl-Novell, S., Lawrence, S. and King, C.J. (2010), Assessing the Future Landscape of Scholarly Communication: An Exploration of Faculty Values and Needs in Seven Disciplines. University of California Center for Studies in Higher Education, Berkeley, CA.

Haustein, S., Peters, I., Bar-Ilan, J., Priem, J., Shema, H. and Terliesner, J. (2014), “Coverage and adoption of altmetrics sources in the bibliometric community", SCIENTOMETRICS, Vol. 101 No. 2, pp. 1145-1163.

Hoffmann, C.P., Lutz, C. and Meckel, M. (2014), "Impact Factor 2.0: Applying Social Network Analysis to Scientific Impact Assessment”, in System Sciences (HICSS), 2014 47th Hawaii International Conference on System Sciences, IEEE, New York, NY, pp. 1576-1585.

Holmberg, K. and Thelwall, M. (2014), "Disciplinary differences in Twitter scholarly communication", SCIENTOMETRICS, Vol. 101 No. 2, pp. 1027-1042.

Hyland, K. (2011), "The presentation of self in scholarly life: Identity and marginalization in academic homepages", English for Specific Purposes, Vol. 30 No. 4, pp. 286-297.

Jacobson, I. (2004), “Use cases-Yesterday, today, and tomorrow”, Software and Systems Modeling, Vol. 3 No. 3, pp. 210-220.

Jamali, H.R., Nicholas, D. and Herman E. (2015), "Scholarly reputation in the digital age and the role of emerging platforms and mechanisms", Research Evaluation, Vol. 25 No. 1, pp. 37-49.

Jeng, W., He, D. and Jiang, J. (2015), “User Participation in an Academic Social Networking Service: A Survey of Open Group Users on Mendeley", Journal of the Association for Information Science and Technology, Vol. 66 No. 5, pp. 890-904.

Jordan, K. (2014), “Academics and their online networks: Exploring the role of academic social networking sites", First Monday, Vol. 19 No. 11, available at: http://dx.doi.org/10.5210/fm.v19i11.4937 (accessed 9 August 2017). 
Kratz, J.E. and Strasser, C. (2015), "Researcher Perspectives on Publication and Peer Review of Data", PLoS ONE, Vol. 10 No. 2, e0117619.

Li, N. and Gillet, D. (2013), "Identifying Influential Scholars in Academic Social Media Platforms", in Proceedings of the International Conference on Advances in Social Networks Analysis and Mining (ASONAM), IEEE, New York, NY, pp. 608-614.

LinkedIn (2016), "LinkedIn: registered members worldwide as of 1st quarter 2016, by country (in millions)", available at: https://www.statista.com/statistics/272783/linkedins-membershipworldwide-by-country/ (accessed 9 August 2017).

LinkedIn (2017), “About Us", available at: https://press.linkedin.com/about-linkedin (accessed 9 August 2017).

Lüders, M. and Brandtzæg, P.B. (2017), “'My children tell me it’s so simple’: A mixed-methods approach to understand older non-users' perceptions of Social Networking Sites", new media \& society, Vol. 19 No. 2, pp. 181-198.

Madhusudhan, M. (2012), "Use of social networking sites by research scholars of the University of Delhi: A study”, International Information \& Library Review, Vol. 44 No. 2, pp. 100-113.

Manca, S. and Ranieri, M. (2017), "Networked Scholarship and Motivations for Social Media use in Scholarly Communication", The International Review of Research in Open and Distributed Learning, Vol. 18 No. 2, available at: http://www.irrodl.org/index.php/irrodl/article/view/2859 (accessed 9 August 2017).

Manca, S. and Ranieri, M. (2016), ““'Yes for sharing, no for teaching!”: Social Media in academic practices", The Internet and Higher Education, Vol. 29, pp. 63-74.

Mas-Bleda, A. and Aguillo, I.F. (2013), "Can a personal website be useful as an information source to assess individual scientists? The case of European highly cited researchers", SCIENTOMETRICS, Vol. 96 No. 1, pp. 51-67.

Mas-Bleda, A., Thelwall, M., Kousha, K. and Aguillo, I.F. (2014), "Do highly cited researchers successfully use the social web?", SCIENTOMETRICS, Vol. 101 No. 1, pp. 337-356.

Meishar-Tal, H. and Pieterse, E. (2017), "Why Do Academics Use Academic Social Networking Sites?" The International Review of Research in Open and Distributed Learning, Vol. 18 No. 1, available at: http://www.irrodl.org/index.php/irrodl/article/view/2643 (accessed 9 August 2017).

Menendez, M., Angeli, A.D. and Menestrina, Z. (2012), "Exploring the Virtual Space of Academia", in Dugdale, J. et al. (Eds.), From Research to Practice in the Design of Cooperative Systems: Results and Open Challenges, Springer, London, UK, pp. 49-63.

Miles, M.B. and Huberman, A.M. (1994), Qualitative Data Analysis: An Expanded Sourcebook, Sage, Thousand Oaks, CA.

Mohammadi, E. and Thelwall, M. (2014), "Mendeley readership altmetrics for the social sciences and humanities: Research evaluation and knowledge flows", Journal of the Association for Information Science and Technology, Vol. 65 No. 8, pp. 1627-1638. 
Murray, M. (2014), “Analysis of a scholarly social networking site: The case of the dormant user”, in Floyd, K.S., Rutner, P. and Gardiner, A. (Eds.), Proceedings of the Seventeenth Annual Conference of the Southern Association for Information Systems (SAIS), Paper 24.

Nández, G. and Borrego, Á. (2013), "Use of social networks for academic purposes: a case study", Electronic Library, Vol. 31 No. 6, pp. 781-791.

Nicholas, D., Herman, E., Jamali, H.R., Bravo, B.R., Boukacem-Zeghmouri, C., Dobrowolski, T. and Pouchot, S. (2015), "New ways of building, showcasing, and measuring scholarly reputation", Learned Publishing, Vol. 28 No. 3, pp. 169-183.

Ortega, J.L. (2015a), "How is an academic social site populated? A demographic study of Google Scholar Citations population”, SCIENTOMETRICS, Vol. 104 No. 1, pp. 1-18.

Ortega, J.L. (2015b), "Disciplinary differences in the use of academic social networking sites", Online Information Review, Vol. 39 No. 4, pp. 520 - 536.

Pscheida, D., Albrecht, S., Herbst, S., Minet, C. and Köhler, T. (2014), Nutzung von Social Media und onlinebasierten Anwendungen in der Wissenschaft: Erste Ergebnisse des Science 2.0-Survey 2013 des Leibniz-Forschungsverbunds Science 2.0, Leibniz-Forschungsverbund, Dresden, Germany.

ResearchGate (2017), “About ResearchGate”, available at: https://www.researchgate.net/about (accessed 9 August 2017).

Rohani, V.A. and Ow, S.H. (2011), "Eliciting Essential Requirements for Social Networks in Academic Environments", in Computers \& Informatics (ISCI), 2011 IEEE Symposium on Computers \& Informatics, IEEE, New York, NY, pp. 171-176.

Rowlands, I., Nicholas, D., Russell, B., Canty, N. and Watkinson, A. (2011), "Social media use in the research workflow", Learned Publishing, Vol. 24 No. 3, pp. 183-195.

Ryan, T. and Xenos, S. (2011), "Who uses Facebook? An investigation into the relationship between the Big Five, shyness, narcissism, loneliness, and Facebook usage", Computers in Human Behavior, Vol. 27 No. 5, pp. 1658-1664.

Tenopir, C., Allard, S., Douglass, K., Aydinoglu, A.U., Wu, L., Read, E. et al. (2011), "Data Sharing by Scientists: Practices and Perceptions", PLoS ONE, Vol. 6 No. 6, e21101.

Thelwall, M. and Kousha, K. (2014), “Academia.edu: Social Network or Academic Network?”, Journal of the Association for Information Science and Technology, Vol. 65 No. 4, pp. 721-731.

Van Noorden, R. (2014), “Online collaboration: Scientists and the social network”, Nature, Vol. 512, pp. 126-129.

Wallis, J.C., Rolando, E. and Borgman, C.L. (2013), "If we share data, will anyone use them? Data sharing and reuse in the long tail of science and technology", PLoS ONE, Vol. 8 No. 7, e67332.

Weller, K. (2015), "Social Media and Altmetrics: An Overview of Current Alternative Approaches to Measuring Scholarly Impact”, in Welpe, I.M., Wollersheim, J., Ringelhan S. and Osterloh, M. 
1

2

3

4

5

6

7

8

9

10

11

12

13

14

15

16

17

18

19

20

21

22

23

24

25

26

27

28

29

30

31

32

33

34

35

36

37

38

39

40

41

42

43

44

45

46

47

48

49

50

51

52

53

54

55

56

57

58

59

60
(Eds.), Incentives and Performance. Governance of Research Organizations, Springer International Publishing, Cham, Switzerland, pp. 261-276.

Williams, A.E. and Woodacre, M.A. (2016), "The Possibilities and Perils of Academic Social Networking Sites”, Online Information Review, Vol. 40 No. 2, pp. 282-294.

XING (2017), „XING knackt 12 Millionen-Mitglieder-Marke“, available at: https://corporate.xing.com/de/newsroom/pressemitteilungen/meldung/xing-knackt-12millionen-mitglieder-marke/ (accessed 9 August 2017). 


\begin{tabular}{|l|l|l|l|l|l|l|}
\hline$(\mathrm{N}=81)$ & $\begin{array}{l}\text { females } \\
(\mathrm{N}=23)\end{array}$ & $\begin{array}{l}\text { males } \\
(\mathrm{N}=58)\end{array}$ & $\begin{array}{l}\text { Germany } \\
(\mathrm{N}=17)\end{array}$ & $\begin{array}{l}\text { Singapore } \\
(\mathrm{N}=15)\end{array}$ & $\begin{array}{l}\text { UK } \\
(\mathrm{N}=16)\end{array}$ & $\begin{array}{l}\mathrm{US} \\
(\mathrm{N}=33)\end{array}$ \\
\hline $\begin{array}{l}\text { Engineering \& } \\
\text { Technology (N=16) }\end{array}$ & 4 & 12 & 0 & 7 & 2 & 7 \\
\hline $\begin{array}{l}\text { Medical \& Health } \\
\text { Sciences (N=12) }\end{array}$ & 4 & 8 & 2 & 0 & 7 & 3 \\
\hline $\begin{array}{l}\text { Natural Sciences } \\
(\mathrm{N}=36)\end{array}$ & 7 & 29 & 12 & 8 & 4 & 12 \\
\hline $\begin{array}{l}\text { Social Sciences } \\
(\mathrm{N}=17)\end{array}$ & 8 & 9 & 3 & 0 & 3 & 11 \\
\hline
\end{tabular}

Table 1a. Overview of participants' field of study included in the analysis of this paper. 
1

2

3

4

5

6

7

8

9

10

11

12

13

14

15

16

17

18

19

20

21

22

23

24

25

26

27

28

29

30

31

32

33

34

35

36

37

38

39

40

41

42

43

44

45

46

47

48

49

50

51

52

53

54

55

56

57

58

59

60

\begin{tabular}{|l|l|l|l|l|l|l|l|}
\hline$(\mathrm{N}=81)$ & $\begin{array}{l}\text { females } \\
(\mathrm{N}=23)\end{array}$ & $\begin{array}{l}\text { males } \\
(\mathrm{N}=58)\end{array}$ & $\begin{array}{l}\text { Germany } \\
(\mathrm{N}=17)\end{array}$ & $\begin{array}{l}\text { Singapore } \\
(\mathrm{N}=15)\end{array}$ & $\begin{array}{l}\text { UK } \\
(\mathrm{N}=16)\end{array}$ & $\begin{array}{l}\mathrm{US} \\
(\mathrm{N}=33)\end{array}$ \\
\hline Junior $(\mathrm{N}=32)$ & 12 & 20 & 6 & 4 & 5 & 17 \\
\hline Midlevel $(\mathrm{N}=24)$ & 5 & 19 & 5 & 9 & 5 & 5 \\
\hline Senior $(\mathrm{N}=25)$ & 6 & 19 & 6 & 2 & 6 & 11 \\
\hline
\end{tabular}

Table 1b. Overview of participants' level of seniority included in the analysis of this paper. 
Journal of Documentation

Page 26 of 28

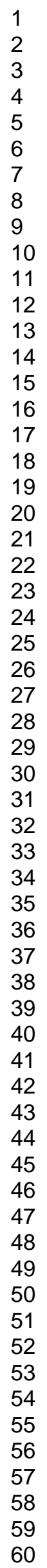




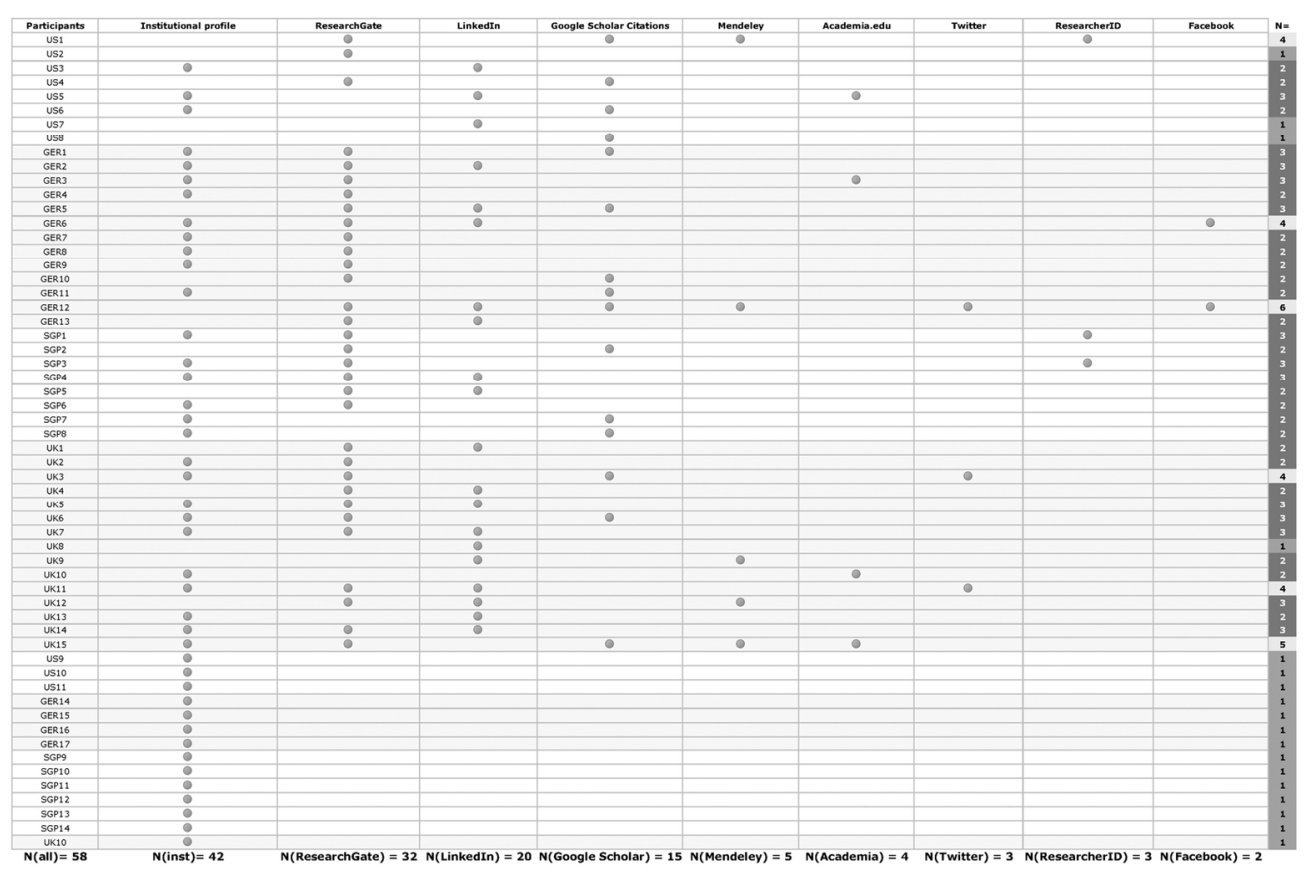

Figure 2. Overview of sites where 58 participants reported having profiles.

$279 \times 184 \mathrm{~mm}(150 \times 150 \mathrm{DPI})$ 


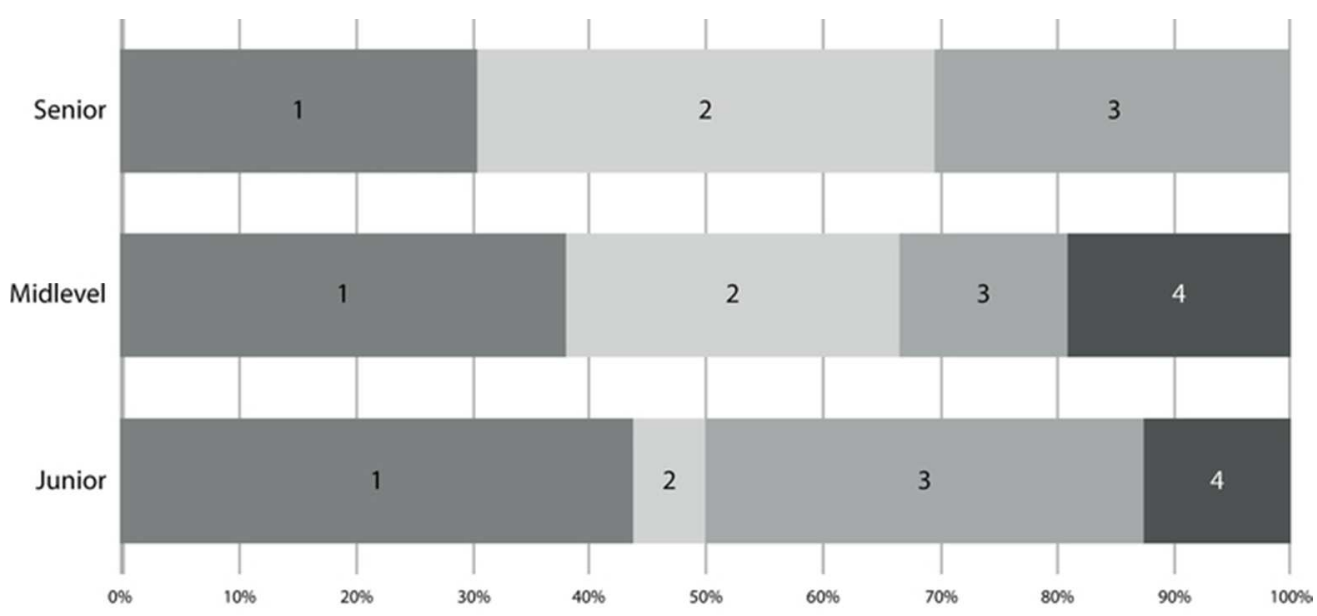

Group 1: Profiles on SNS are or can be useful for me

Group 2: Profiles on SNS are not important enough for me

- Group 3: Profiles on SNS don't work for me

Group 4: Profiles on SNS may hurt my career

Figure 3. Likelihood of uptake of academic profiles on SNS from group 1 very likely (left side) to group 4 highly unlikely (right side) grouped by level of seniority.

$123 \times 75 \mathrm{~mm}(150 \times 150 \mathrm{DPI})$ 